\title{
AS QUATRO DIMENSÕES DA RELAÇÃO HOMEM - MEIO AMBIENTE
}

\author{
Job Antonio Garcia Ribeiro ${ }^{1}$ \\ Osmar Cavassan ${ }^{2}$
}

Resumo: Neste ensaio teórico introdutório, pretendemos trazer algumas contribuições para a temática ambiental, em especial para as discussões a respeito da relação entre o homem e o meio ambiente. Apresentamos a necessidade de se adotar, ao menos, quatro perspectivas ao se discutir as razões pelas quais existem diferentes atitudes e valores do Homo sapiens para com o meio ambiente físico, biológico e social: a perspectiva filogenética, a ontogenética, a sociogenética e a microgenética. Para tanto, nos apoiamos nos trabalhos psicológicos de Vygotsky e nas obras da teoria perceptual de Yi-Fu Tuan. Pautados nessas quatro dimensões, buscamos, ainda, ampliar nosso entendimento sobre o conceito de meio ambiente, compreendido como uma esfera abstrata, construída individualmente no intercâmbio sociocultural.

Palavras-chave: Interação homem - meio ambiente. Meio ambiente humano. Senso de meio ambiente.

\section{THE FOUR DIMENSIONS MAN-ENVIRONMENT'S RELATION}

Abstract: In this introductory theoretical essay, we intend to bring some contributions to environmental issues, in particular for discussions about the relationship between man and the environment. We present the need to adopt, at least, four perspectives to discuss the reasons why there are different attitudes and values of Homo sapiens to the physical, biological and social environment: phylogenetic, ontogenetic, microgenetic and sociogenetic perspective. Therefore, we support on the psychological work of Vygotsky and the works of perceptual theory of Yi-Fu Tuan. Guided by these four dimensions, we seek also expand our understanding of the concept of environment, understood as an abstract sphere constructed individually in socio-cultural exchanges.

Keywords: Interaction man - environment. Human environment. Sense of the environment.

\footnotetext{
${ }^{1}$ Mestre em Educação para a Ciência. Programa de Pós-graduação em Educação para a Ciência, Faculdade de Ciências, Universidade Estadual Paulista "Júlio de Mesquita Filho" (UNESP), Bauru, São Paulo, Brasil, job_ribeiro2005@yahoo.com.br.

2 Professor Adjunto. Programa de Pós-graduação em Educação para a Ciência, Faculdade de Ciências, Universidade Estadual Paulista "Júlio de Mesquita Filho" (UNESP), Bauru, São Paulo, Brasil, cavassan@fc.unesp.br.
} 


\section{LAS CUATRO DIMENSIONES DE LA RELACIÓN HOMBRE - MEDIO AMBIENTE}

Resumen: En este ensayo teórico introductorio, pretendemos traer algunas contribuciones para la temática ambiental, en especial para las discusiones a respecto de la relación entre el hombre y el medio ambiente. Presentamos la necesidad de adoptar, al menos, cuatro perspectivas al discutir las razones por las que existen diferentes actitudes y valores del Homo sapiens para con el medio ambiente físico, biológico y social: la perspectiva filogenética, la ontogenética, la sociogenética y la microgenética. Para esto, nos apoyamos en los trabajos psicológicos de Vygotsky y en las obras de la teoría perceptiva de Yi-Fu Tuan. Pautados en estas cuatro dimensiones, procuramos, incluso, ampliar nuestro entendimiento sobre el concepto de medio ambiente, comprendido como una esfera abstracta, construida individualmente en el intercambio sociocultural.

Palabras clave: Interacción hombre - medio ambiente. Medio ambiente humano. Sentido de medio ambiente.

\section{Introdução}

É possível observarmos inúmeros trabalhos que buscam caracterizar e descrever a relação entre o homem e o meio ambiente (sociedade - ambiente ou homem - natureza) nos diferentes contextos históricos (COLLINGWOOD, 1978; LENOBLE, 2002; GONÇALVES, 2005; CARVALHO, 2008; THOMAS, 2010), bem como estudos a respeito das influências que subjazem às ações humanas na relação com o meio ambiente e em suas representações (TUAN, 1980; VESTENA, 2011).

Todavia, algumas observações fazem-se pertinentes: a primeira delas é que há uma tendência a se enfatizar a influência da cultura e das relações sociais no modo pelo qual os indivíduos interagem com os elementos ambientais (físicos, biológicos e sociais) e os representam, negligenciando, muitas vezes, outros aspectos que consideramos importantes. Consequentemente, isso acarreta certa desconsideração do homem como ser biológico, que passa a ser representado apenas pelo viés das Ciências Sociais e Humanas.

Por outro lado, observamos, também, estudos que buscam descrever as causas biológicas das relações humanas com o meio ambiente (WILSON, 1981), porém essa abordagem é tida, frequentemente, como inadequada por não considerar a complexidade das organizações sociais. E, assim, um mesmo objeto de estudo (a relação homem - meio ambiente), passa a ser interpretado de modo distinto, ora por um viés estritamente biológico, ora por um viés predominantemente social.

O que pretendemos não é fomentar essa postura dicotômica, defendendo um determinismo social ou um determinismo biológico, mas, sim, buscar elaborar uma espécie de síntese. Uma síntese entendida não como a simples soma ou justaposição, mas como a 
emergência de algo novo, anteriormente não existente, que contemple os aspectos orgânicos, psicológicos e sócio-históricos da relação entre o homem e o meio ambiente.

Para tanto, nos apoiamos nos trabalhos perceptuais de Tuan e nas ideias centrais de Vygotsky, que buscava reunir, em um mesmo modelo explicativo, tanto os mecanismos do funcionamento psicológico como o desenvolvimento do indivíduo e da espécie humana, ao longo de um processo histórico, fazendo uso de uma abordagem que podemos denominar de integrativa.

Almejamos destacar a pertinência de incluirmos questões do homem biológico na abordagem do homem social e, assim, reciprocamente, reconhecendo nossa herança animal e ao mesmo tempo a importância da cultura (TUAN, 1983). Propomos uma compreensão a respeito dos determinantes que condicionam nossa relação com o meio ambiente, sendo este entendido em sua conotação mais ampla, ou seja, incluindo o meio ambiente físico (geográfico), o biológico e o social (humanizado).

Este trabalho contempla, portanto, uma discussão das quatro dimensões da relação homem - meio ambiente, deixando claro que não se trata de uma abordagem reducionista, mas, sim, integrativa. Por meio das colocações que se seguem, esperamos ampliar a discussão da temática ambiental, fornecendo argumentos para um conceito, também integrativo, de meio ambiente.

\section{Homem e meio ambiente: uma abordagem multidimensional}

De acordo com Oliveira (1995), os trabalhos de Lev Semenovich Vygotsky (18961934) se caracterizaram por tentar integrar, numa única perspectiva, o homem enquanto ser biológico e ser social, isto é, enquanto membro da espécie humana e, ao mesmo tempo, participante de um processo histórico. É justamente essa ideia central que pretendemos desenvolver em nosso estudo sobre a relação homem - meio ambiente.

Podemos dizer que as formulações teóricas de Vygotsky $(1991,2001)$ se sustentam em três pressupostos básicos, os quais estão incluídos nas seguintes afirmações: (1) as funções psicológicas tem um suporte biológico; (2) o funcionamento psicológico fundamenta-se nas relações sociais entre o indivíduo e o mundo exterior, as quais se desenvolvem num processo histórico; (3) a relação homem/mundo é uma relação mediada por sistemas simbólicos.

Esses pressupostos articulados nos permitem dizer que o homem, enquanto espécie biológica, possui uma existência material que define limites e possibilidades para o seu desenvolvimento e suas estruturas, em especial as cognitivas, as quais são construídas ao longo da história da espécie e do seu desenvolvimento individual. Ao mesmo tempo em que existem processos elementares de origem biológica, há também as funções psicológicas superiores (que envolvem o controle consciente do comportamento, a ação intencional e a liberdade do indivíduo em relação às características do momento e do espaço presentes), de origem sociocultural e é do entrelaçamento dessas linhas que nasce a história do comportamento humano (VYGOTSKY, 1991; VYGOTSKY; LURIA, 1996).

Podemos supor que essas funções psicológicas superiores, das quais trata Vygotsky, são determinantes nas ações dos indivíduos e no comportamento que possuem frente aos mais diversos contextos e situações. Desse modo, concordamos com Tuan $(1980,1983)$ ao afirmar que a cultura e a natureza da experiência histórica das pessoas tem grande influência na interpretação que terão do meio ambiente e nas relações que serão estabelecidas.

Vygotsky compreende a origem e o desenvolvimento dos processos psicológicos humanos, isto é, sua gênese, por meio da abordagem de diferentes níveis ou domínios 
genéticos: (1) o filogenético, que diz respeito ao desenvolvimento da espécie humana; (2) o ontogenético relacionado ao desenvolvimento do indivíduo; (3) o sociogenético referente à história dos grupos sociais; e (4) o microgenético, que se refere ao desenvolvimento de aspectos específicos do repertório psicológico dos sujeitos (OLIVEIRA, 2006).

Nesse sentido, o percurso de desenvolvimento do ser humano e, consequentemente, suas ações e as relações que constrói, são em parte definidos pelos processos de maturação do organismo individual, pertencentes à espécie, mas ao mesmo tempo, influenciados pelo contato do indivíduo com um determinado contexto cultural. Embora estejamos sob influências culturais, existem certos imperativos biológicos (TUAN, 1983).

Em outras palavras, o homem nasce com certas características próprias da espécie (por exemplo, a capacidade de enxergar por dois olhos, que permite a percepção tridimensional, ou a capacidade de receber e processar informação auditiva), mas as chamadas funções psicológicas superiores, aquelas que envolvem consciência, intenção, planejamento, ações voluntárias e deliberadas, dependem de processos de aprendizagem (OLIVEIRA, 2006, p.56).

Esse processo de aprendizagem inclui as relações entre os indivíduos e o mundo, e entre os próprios sujeitos, ou seja, as relações interpessoais que são mediadas por sistemas simbólicos, construídos socialmente.

Nos trabalhos de Tuan (1980, 1983) podemos encontrar ideias semelhantes à abordagem vygotskyana. Na obra Topofilia, o autor busca interpretar como se dá a percepção humana e a construção de valores ambientais em diferentes níveis: no nível das espécies, no nível dos grupos e no nível dos indivíduos. Para o autor (1980), os valores e atitudes estariam relacionados às nossas necessidades biológicas, à nossa cultura e, também, aos valores pessoais construídos no intercâmbio com a sociedade.

Acreditamos, portanto, que ao considerarmos o homem não podemos negligenciar suas particularidades morfofisiológicas e evolutivas (biológicas), tampouco seu processo de desenvolvimento intelectual e físico ao qual está submetido ao longo de seu período de vida. Isso implica afirmar que a relação humana com o meio ambiente deve ser vista por meio de uma perspectiva não somente social, mas também ecológica e temporal.

Consequentemente, para entendermos as diferentes atitudes em relação ao meio ambiente, "necessitamos [por exemplo] conhecer alguma coisa da fisiologia humana e da diversidade de temperamento" (TUAN, 1980, p.53), como também examinar a herança biológica do indivíduo e suas relações interpessoais. No nível de grupo, deve-se conhecer a história cultural e a experiência desse grupo em seu contexto. Assim, defendemos que a atribuição de significados e valores aos elementos do meio ambiente se deve a três condições: à cultura, às características biológicas humanas e às experiências pessoais.

Neste trabalho introdutório, partimos do pressuposto de que para se discutir a respeito de qualquer relação entre o Homo sapiens com o seu meio ambiente (físico, biológico ou social), é importante considerarmos essas quatro perspectivas ou dimensões: a filogenética, a ontogenética, a sociogenética e a microgenética.

Vale ressaltar que, embora apresentemos essas dimensões em tópicos, elas estão concatenadas e estritamente relacionadas. Contemplam um olhar multidimensional e, portanto, só se pode entender o significado de cada uma compreendendo-se as relações que existem entre elas. 


\subsection{A dimensão filogenética}

Não podemos desconsiderar que a dependência dos seres vivos em relação às características do meio ambiente varia de uma espécie para outra. Em nível taxonômico, as relações entre os animais e o meio ambiente são diferentes das relações que os vegetais possuem, por exemplo. Alguns animais podem procurar o seu alimento, seu abrigo, fugir de seus predadores ou ter mais facilidade que os vegetais para encontrar membros da sua própria espécie e proceder à reprodução sexuada (BRANCO; ROCHA, 1980). Logo, possuem uma ampla margem de controle sobre o meio em que vivem, pois podem se deslocar de um local desfavorável e buscar ativamente outro.

Entretanto, os organismos sésseis não possuem essas mesmas relações, pois necessitam viver nas condições em que se encontram. Estão expostos a forças de seleção natural, de uma forma particularmente intensa, e seu meio ambiente adquire um significado distinto. Para um vegetal, o meio ambiente é o local físico onde se encontra fixado; para um animal livre, o meio, além de mais amplo, pode ser mais estável, uma vez que pode, quase sempre, buscar um local que lhe ofereça condições mais favoráveis (BRANCO; ROCHA, 1980; BEGON; TOWNSEND; HARPER, 2007).

No entanto, ao adentrarmos na esfera humana, a noção de meio ambiente adquire outro sentido, pois para o Homo sapiens o meio ambiente é mais passível de mudanças convenientes (GOODE, 1904). É a nossa espécie a que mais desenvolveu (e desenvolve) a capacidade de deslocamento e a construção de abrigos e refúgios, alterando o meio em que vive para atender às suas necessidades biológicas, como também aquelas correspondentes aos conceitos de conforto, em nível individual, e de desenvolvimento, em nível coletivo (BRANCO, 1995).

Somos uma das linhagens que apresenta e estabelece mais interações com as demais espécies e impomos, direta ou indiretamente, intensas mudanças nas associações já existentes. Atuando como predadores, competidores, mutualistas ou parasitas, iniciamos associações, diariamente, seja em virtude do desenvolvimento, da domesticação de espécies, da manipulação genética, das alterações ambientais ou de diversas outras atividades (BOEGER, 2009).

Nossa espécie é, possivelmente, uma das mais importantes do ponto de vista ecológico (mas não em termos valorativos), pois é a que possui mais condições (devido à sua racionalidade) de impor limites ao desenvolvimento das demais espécies. Possuímos particularidades fisiológicas que foram adquiridas e desenvolvidas durante o processo evolutivo, processo este a que todos os seres estão submetidos.

As percepções humanas que influenciam nas relações ambientais físicas, biológicas e sociais encontram-se, portanto, limitadas ao aparato biológico de nossa espécie. Somos, predominantemente, um animal visual; possuímos uma visão estereoscópica (olhos frontais) que nos possibilita enxergar tridimensionalmente. Nossa sensibilidade tátil fornece uma grande quantidade de informações sobre o mundo. E, embora nossa audição não seja tão desenvolvida em relação a outros animais, é também importante para a apreensão da realidade (TUAN, 1980).

A visão humana, por exemplo, está organizada para perceber luz, que revelará pontos, linhas, cores, movimentos, profundidade; a audição permite a percepção de sons em diferentes timbres, alturas e intensidades; o tato permite perceber pressão, temperatura, textura. Os limites dessas e das demais sensações são definidos pelas características do aparato perceptivo da espécie humana: não escutamos ultrassons, como o morcego e o golfinho; não percebemos movimento na água com a sutileza dos peixes; não somos capazes de nos orientar no espaço a 
partir de informações sobre temperatura, como as cobras (OLIVEIRA, 1995, p.73).

Percebemos o mundo, simultaneamente, por meio de todos os sentidos, e um sentido colabora com o outro de modo que, juntos, auxiliam na estruturação do pensamento.

Para Tuan (1980) a espécie humana compartilha percepções comuns, um mundo comum, em virtude de possuir órgãos similares, selecionados durante um longo processo evolutivo. Percepções estas que se diferenciam daquelas experienciadas por outros animais.

Existem, portanto, aspectos psicológicos ou características comuns à percepção humana que nos permitem perceber o mundo que nos cerca e que devem ser considerados, dentre os quais podemos destacar:

a) Percep̧ãa escalar: esse aspecto psicológico da percepção humana nos possibilita organizar em certa escala (espacial ou valorativa) os objetos do meio ambiente (físico, biológico e social). Essa escala, por sua vez, influencia fortemente o modo pelo qual interagimos com esses objetos e fenômenos. Bactérias e pequenos insetos, por exemplo, estariam além da capacidade humana de empatia, pois o laço emocional entre o homem e alguns seres dificilmente persiste além de certo tamanho (TUAN, 1980).

b) Segmentação: nós humanos buscamos estruturar o espaço e, por isso, tendemos a segmentar os continnuns da natureza. Criamos categorias abstratas e artificiais para podermos organizar os elementos e fenômenos em nossa mente e, consequentemente, agirmos sobre eles. O conceito de ecossistema é um exemplo de uma categoria científica elaborada para compreender as partes de um ambiente.

c) Egocentrismo: essa característica humana pode ser entendida como o hábito de ordenar os componentes do mundo, no qual os valores de tais componentes diminuem na medida em que se distanciam do self, do $e u$. Individualmente ou coletivamente, tendemos a perceber o mundo com o self sendo o centro, pois "a consciência fica no indivíduo, [e, assim,] é inevitável uma estruturação egocêntrica do mundo" (TUAN, 1980, p.34,). O egocentrismo e o etnocentrismo (entendido como um egocentrismo coletivo e considerado uma espécie de defesa contra as forças homogeneizadoras) são traços humanos universais, embora suas intensidades variem entre os indivíduos e os grupos.

Embora essa visão de centralidade e superioridade possa ser interpretada de maneira extremista (tal como se dá no caso do xenofobismo), é, provavelmente, necessária para a manutenção da própria cultura. Tuan (1980) cita vários exemplos de etnocentrismo em povos antigos, por meio de estudos realizados com mapas, e complementa que é conhecida a tendência de exagerar o tamanho e a qualidade do território natal em detrimentos dos territórios vizinhos e distantes.

d) Linguagem simbólica: diferentemente dos demais animais, desenvolvemos um comportamento simbólico, isto é, uma linguagem abstrata de sinais e símbolos. É devido a essa capacidade que construímos mundos mentais para nos relacionarmos e para poder atuar sobre a realidade externa e sobre o meio ambiente. Por meio dessa linguagem, estruturamos também o mundo em um número ilimitado de categorias.

Apesar de sermos dotados de órgãos sensoriais, igualmente aos demais primatas, temos a capacidade de elaborarmos símbolos e atribuir significados aos fenômenos e objetos que nos cercam (TUAN, 1983). E essa é uma das mais importantes e complexas capacidades humanas.

Pensamos em objetos ausentes, imaginamos eventos não vividos, planejamos ações etc. Essas atividades se diferenciam dos mecanismos mais elementares, como as ações reflexas, reações automatizadas ou processos de associações simples entre eventos, que 
podem ser observados em macacos antropóides (VYGOTSKY, 2001; VYGOTSKY; LURIA, 1996).

Para Vygotsky, a capacidade simbólica nos permite interagir com o mundo de maneira mediada. A presença desses elementos mediadores (instrumentos ou símbolos) introduz um elo a mais nas relações organismo/meio, tornando-as mais complexas e, ao longo do desenvolvimento do indivíduo, ou seja, de sua ontogênese, as relações mediadas passam a predominar sobre as relações diretas (OLIVEIRA, 1995).

Vygotsky $(1991,2001)$ trabalha, então, com a noção de que a relação do homem com o mundo e, portanto, do homem com o meio ambiente (seja ele físico, biológico ou social) não é uma relação direta, mas, fundamentalmente, mediada por instrumentos e signos.

Para Oliveira (1995) e Vygotsky (2001), os instrumentos são entendidos como elementos interpostos entre o trabalhador e seu objeto de trabalho, que ampliam as possibilidades de transformação da natureza. É, portanto, o trabalho que pela ação transformadora humana une homem e natureza, criando a cultura e a história humanas. É no trabalho que se desenvolve a atividade coletiva, as relações sociais e a criação e a utilização de instrumentos.

Embora alguns animais façam também uso de instrumentos, diferentemente da espécie humana, eles

[...] não produzem, deliberadamente, instrumentos com objetivos específicos, não guardam os instrumentos para uso futuro [...]. São capazes de transformar o ambiente num momento específico, mas não desenvolvem sua relação com o meio num processo histórico-cultural, como o homem (OLIVEIRA, 1995, p.29).

Os signos, por sua vez, agem como instrumentos da atividade psicológica de maneira análoga, representam ou expressam objetos, eventos e situações. É essa capacidade de lidar com representações que substituem o próprio real que possibilita ao homem libertar-se do espaço e do tempo presentes, fazer relações mentais na ausência das próprias coisas, imaginar, fazer planos e ter intenções. $\mathrm{O}$ uso de signos conduz os seres humanos a uma estrutura específica de comportamento, que se destaca do desenvolvimento biológico e cria novas formas de processos psicológicos enraizados na cultura (VYGOTSKY, 1991, 2001). São, portanto, essas representações mentais da realidade exterior, os principais mediadores a serem considerados na relação do homem com o mundo (OLIVEIRA, 1995).

Seja fazendo uso de instrumentos ou de signos, o processo de mediação sofre transformações ao longo do desenvolvimento do indivíduo, que deixa de necessitar de marcas externas e passa a utilizar signos internos, ou seja, representações mentais que substituem os objetos do mundo real (VYGOTSKY, 2001). Aqui está, novamente, a dimensão ontogenética.

Todavia, não somente a ontogenia está ligada ao uso de mediadores, mas também a dimensão sociogenética e microgenética. Isso porque, o grupo cultural onde o indivíduo se desenvolve fornece formas e maneiras de organizar o real, e é a partir de sua experiência particular com o mundo e do contato com as formas culturalmente determinadas de organização desse real que irá construir seu sistema particular de signos (OLIVEIRA, 1995).

A percep̧cão escalar, a segmentação e o egocentrismo, aliados à linguagem simbólica nos dão uma capacidade única, a de atribuir significados aos fenômenos e objetos da realidade exterior. Logo, os sistemas simbólicos exercem um papel fundamental na comunicação entre os indivíduos e no estabelecimento de significados compartilhados que permitem interpretações de objetos, eventos e situações do mundo real. Contudo, isso se dá em um 
processo temporal, pois a percepção que possuímos do meio ambiente hoje, não necessariamente será a mesma de amanhã.

\subsection{A dimensão ontogenética}

Para Mason e Langenheim (1957), a sequência das demandas ambientais e relacionais de qualquer ser vivo é direcionada pelas necessidades inerentes ao seu ciclo ontogenético. Existe uma correlação entre ontogenia e meio ambiente: em alguns casos as demandas ambientais seguem uma sequência controlada pela ontogenia, em outros, seguem uma sequência controlada pela alteração do próprio meio.

Essa abordagem torna-se importante, pois, assim como os autores, questionamos que ponto do ciclo de vida de determinado organismo devemos utilizar para traçar a definição de meio ambiente. Acreditamos que esse conceito, quando acrescido da noção de tempo, amplia nossas discussões a respeito da relação homem - meio ambiente.

Ao considerarmos essas afirmações, podemos pensar que as interações e relações que possuímos com o meio ambiente também variam temporalmente. De acordo com Tuan (1980, p.67), "a amplitude das respostas humanas para o mundo é aumentada além do que normalmente estudam os cientistas sociais, quando nos lembramos de considerar os estágios do ciclo de vida".

No que se refere à idade do indivíduo, os trabalhos piagetianos evidenciam que a experiência espacial, por exemplo, é diferente no decorrer do desenvolvimento humano (TUAN, 1980). Na obra A representação do mundo na criança (2005), Jean Piaget (1896-1980), juntamente com outros pesquisadores, busca identificar e analisar as representações criadas espontaneamente pelas crianças ao longo dos diferentes estágios de seu desenvolvimento intelectual.

Para ele, a criança não distingue o mundo psíquico do mundo físico, não observa limites precisos entre o ego e o mundo exterior e, muitas vezes, acaba por considerar vivo e consciente um grande número de corpos que, para nós, adultos, são inertes. É esse fenômeno, denominado por Piaget de animismo, que se torna função de numerosas particularidades essenciais do pensamento infantil.

Em um primeiro estágio, tudo o que tem uma atividade qualquer é consciente, ainda que seja imóvel. A criança afirma que todo objeto pode ser sede de consciência em determinado momento, isto é, quando o objeto for ativo em qualquer grau ou quando for sede de uma ação. Logo, para ela, uma rocha pode não sentir nada, mas se a deslocamos ou a molhamos, ela o sentirá (PIAGET, 2005).

Para as crianças categorizadas no segundo estágio de animismo, a consciência está reservada aos corpos em movimento. Assim, o sol e uma bicicleta são conscientes, mas uma mesa não. Nota-se que a consciência está, agora, reservada aos objetos que costumam estar em movimento, ou cuja atividade própria é estar em movimento, como os astros, as nuvens, os rios, os ventos, os veículos, o fogo etc. (PIAGET, 2005).

No terceiro estágio descrito por Piaget, onde há uma espécie de animismo mais refletido, a criança passa a fazer uma distinção entre o movimento próprio e o movimento recebido do exterior. Seriam, os primeiros, os únicos dotados de consciência. Por fim, ao longo de um quarto estágio, a consciência é reservada aos animais, embora haja casos intermediários.

Ao tratar da noção de vida com as crianças, perguntando se alguns objetos são vivos e por que, esses mesmos estágios surgem. No primeiro, é considerado vivo tudo o que tem uma atividade ou mesmo uma função ou utilidade, sejam quais forem. Ao longo do estágio subsequente, a vida é definida pelo movimento, sendo todo o movimento 
considerado como contendo uma parte da espontaneidade. Já no terceiro estágio, a criança distingue o movimento próprio e o movimento recebido, e a vida é identificada com o primeiro desses movimentos. Por fim, no decorrer do quarto estágio, a vida é reservada aos animais, ou aos animais e às plantas (PIAGET, 2005).

Esses quatro estágios que descrevem os processos respectivos de evolução da noção de consciência e vida, correspondem aos tipos de sistematização entre os quais o pensamento espontâneo da criança oscila.

Essas colocações nos possibilitam pensar que, em diferentes fases de nosso desenvolvimento ontogenético, percebemos os objetos e fenômenos do meio ambiente de maneira distinta e, portanto, construímos relações para com esses mesmos objetos e fenômenos que estão sujeitas a constantes modificações. Ao longo de nosso desenvolvimento, a percepção torna-se cada vez mais um processo complexo, que se distancia das determinações fisiológicas dos órgãos sensoriais, embora continue a basear-se nas possibilidades desses órgãos físicos (TUAN, 1980, 1983; OLIVEIRA, 1995). Assim, construímos o meio ambiente e as relações para com ele no decorrer de nossas vidas.

Outro ponto a destacar, discutido na dimensão sociogenética, é que o sistema de relações e generalizações contido numa palavra também se modifica ao longo do desenvolvimento. Segundo Oliveira (1995), ao tomar posse dos significados expressos pela linguagem, a criança os aplica a seu universo de conhecimentos sobre o mundo, a seu modo particular de recortar sua experiência.

No decorrer de seu desenvolvimento, que é marcado pela interação verbal com outros membros da sociedade, o indivíduo vai ajustando seus significados de modo a aproximá-los, cada vez mais, dos conceitos predominantes no grupo cultural e linguístico de que faz parte. Assim, "os significados continuam a ser transformados durante todo o desenvolvimento do indivíduo, ganhando contornos peculiares quando se inicia o processo de aprendizagem escolar" (OLIVEIRA, 1995, p.50).

Nascemos com certas possibilidades de percepção definidas pelas características sensoriais humanas, mas, ao longo do tempo, através da internalização da linguagem e dos conceitos e significados culturalmente desenvolvidos, a percepção deixa de ser uma relação direta entre nós e o meio, passando a ser mediada por conteúdos culturais (VYGOTSKY, 2001; OLIVEIRA, 1995).

Em um trabalho realizado com 240 estudantes de diferentes escolas, com idade entre 8 e 14 anos, Vestena (2011) observou uma tendência moderada do Conbecimento Ambiental aumentar com a idade ou nível de desenvolvimento cognitivo. Para ter um Conhecimento Ambiental no nível que chamou de sistêmico (os demais eram: sistêmico parcial e preliminar), crianças e adolescentes necessitariam de estruturas operativas que lhes permitisse compreender a reversibilidade, a mobilidade e as transformações.

Contudo, a autora também observou que, o que denominou de Juízo Moral Ambiental, embora tenha apresentado variações, não dependeu da idade do sujeito, mas, possivelmente, dos conceitos e valores construídos por si próprios na interação social e da frequência de atividades de Educação Ambiental promovedoras de cooperação (VESTENA, 2011)

Essa observação nos leva a refletir sobre a construção de valores e a importância que a dimensão sócio-histórica ou cultural possui, juntamente com as demais perspectivas, na interpretação das relações homem - meio ambiente.

\subsection{A dimensão sociogenética}


Essa dimensão se refere, como já anunciamos, à construção social das relações humanas para com o meio ambiente, que são elaboradas temporalmente. É, talvez, a perspectiva mais abordada nos trabalhos com temática ambiental, contudo, como queremos ressaltar, não deve ser a única e pode ser visualizada do ponto de vista psicológico.

Segundo Tuan (1980), a cultura pode influenciar a percepção que temos do mundo. Cada cultura possui sua própria interpretação e cada grupo, por julgar sua interpretação mais adequada, crê nela como verdadeira, apegando-se fortemente a ela. "Pessoas de diferentes culturas diferem na forma de dividir seu mundo, de atribuir valores as suas partes [...]" (TUAN, 1983, p.39).

Um visitante e um nativo, por exemplo, focalizam aspectos diferentes do mesmo meio ambiente. A percepção do primeiro geralmente se reduz a compor quadros, ao passo que o nativo tem uma atitude complexa derivada de sua imersão na totalidade do meio ambiente (TUAN, 1980).

O ponto de vista do visitante, por ser simples, é facilmente enunciado e sua avaliação é essencialmente estética, uma vez que é a visão de um estranho, que julga pela aparência, por algum critério formal de beleza. Seu entusiasmo, não menos que sua postura crítica, pode ser superficial. No entanto, o julgamento do visitante é, muitas vezes, válido. Sua principal contribuição é a perspectiva nova, pois é capaz de perceber méritos e defeitos em um meio ambiente, que não são mais visíveis para o residente. Outro exemplo de diferentes perspectivas e consequentes ações frente ao meio ambiente pode ser observado com exploradores e povoadores (TUAN, 1980).

Podemos, ainda, dizer que qual órgão do sentido seja mais exercitado varia não somente de acordo com o indivíduo, mas também com a cultura. $\mathrm{Na}$ sociedade moderna, o homem tem que confiar mais e mais na visão, pois o seu espaço caracteriza-se por um quadro ou matriz de objetos. Sem objetos e fronteiras, o espaço torna-se vazio, diferentemente da noção de espaço que tem um beduíno que vive no deserto. Logo, os elementos culturais afetam até mesmo as habilidades espaciais das pessoas (TUAN, 1983).

Outrossim, embora todos os seres humanos tenham órgãos dos sentidos similares, o modo como suas capacidades são utilizadas e desenvolvidas começa a se divergir na tenra idade. Como resultado, não somente as atitudes para com o meio ambiente diferem, mas também a capacidade real dos sentidos, de modo que uma pessoa de determinada cultura pode desenvolver um olfato aguçado para perfumes, enquanto que a de outra adquire profunda visão estereoscópica (TUAN, 1980).

Nas culturas em que o papel dos sexos é fortemente diferenciado, por exemplo, homens e mulheres olharão diferentes aspectos do meio ambiente e, muito provavelmente, adotarão atitudes diferentes para com ele (TUAN, 1980). É, também, o que apontam os estudos de Ribeiro, Cavassan e Caramaschi (2011, 2013), onde além do caráter social, estaria presente, na determinação de interesses pelos fenômenos ambientais, a questão biológica.

Nesse sentido, os conceitos e representações da natureza, do ambiente ou do meio ambiente podem variar conforme os grupos sociais de diferentes lugares e épocas, pois são construídos na medida em que as relações socioculturais se desenvolvem (COLLINGWOOD, 1978; LENOBLE, 2002; GONÇALVES, 2005).

Essa influência da cultura sobre as representações criadas é amplamente discutida por Vygotsky (1991, 2001). Para o psicólogo russo, a dimensão sociocultural do desenvolvimento humano não se refere apenas a um amplo cenário ou pano de fundo onde se desenrola a vida individual, tampouco a fatores abrangentes como o país onde o indivíduo vive, e o nível socioeconômico, mas principalmente ao papel do grupo cultural 
como fornecedor de um mundo estruturado, onde todos os elementos estão carregados de significados (OLIVEIRA, 1995).

A interação face a face entre indivíduos particulares desempenha um papel fundamental na construção do ser humano: é através da relação interpessoal concreta com outros homens que o indivíduo vai chegar a interiorizar as formas culturalmente estabelecidas de funcionamento psicológico. Portanto, a interação social, seja diretamente com outros membros da cultura, seja através dos diversos elementos do ambiente culturamente estruturado, fornece a matéria prima para $\mathrm{O}$ desenvolvimento psicológico do indivíduo (OLIVEIRA, 1995, p.38).

Isso não implica, necessariamente, cairmos em um determinismo social. Vygotsky (1991) lembra-nos que esse processo no qual o indivíduo internaliza a matéria-prima fornecida pela cultura não é, pois, um processo de absorção passiva, mas de síntese. Significa dizer que ao longo do seu desenvolvimento o indivíduo toma posse das formas de comportamento fornecidas pela cultura, num processo em que as atividades externas e as funções interpessoais transformam-se em atividades internas, intrapsicológicas, portanto, particulares.

A cultura atuaria como um palco de negociações, onde os sujeitos estão num constante movimento de recriação e reinterpretação das informações, dos conceitos e dos significados. "A vida social é um processo dinâmico, onde cada sujeito é ativo e onde acontece a interação entre o mundo cultural e o mundo subjetivo de cada um" (OLIVEIRA, 1995, p.38), e onde estão em interação a história da espécie (filogênese), a história do organismo individual (ontogênese), a história do grupo cultural (sociogênese) e os processos e experiências vividas por cada um (microgênese).

A dimensão social torna-se importante, pois nos permite refletir a respeito dos significados que os grupos de pessoas dão às palavras. Uma vez que os significados são construídos ao longo da história das sociedades, com base nas relações dos homens com o mundo físico, biológico e social em que vivem, eles estão em constante transformação; não são, pois, estáticos.

Do ponto de vista da psicologia, o significado de cada palavra é uma generalização ou um conceito; é um componente essencial da palavra e, ao mesmo tempo, um ato de pensamento. É no significado que se encontra a unidade das duas funções básicas da linguagem: o intercâmbio social e o pensamento generalizante. "São os significados que vão propiciar a mediação simbólica entre o indivíduo e o mundo real, constituindo-se no 'filtro' através do qual o indivíduo é capaz de compreender o mundo e agir sobre ele" (OLIVEIRA, 1995, p.48).

Assim, e tomando os dizeres de Oliveira (1995) como modelo - ao dizer a palavra meio ambiente estou enunciando uma palavra que tem um significado. Esse significado, além de possibilitar a comunicação entre os membros do grupo no qual estou inserido, define um modo de organizar o mundo real de forma que a alguns objetos/fenômenos essa palavra se aplica e a outros não. O problema é que, no caso dessa expressão, ainda não há consenso de seu significado.

Essa abordagem na qual os grupos constroem coletivamente significados está muito próxima da ideia de representação social tratada por Reigota (1998). Apoiando-se nos trabalhos sociológicos de Émile Durkheim (1858-1917) e de Serge Moscovici (1928-), que procuravam discutir a importância das representações dentro de uma coletividade e como elas influenciavam nas decisões tomadas individualmente, o educador ambiental buscou identificar as representações sociais que um grupo de professores em formação possuía do meio ambiente. 
No entanto, não podemos negligenciar que, além de significados, temos também os sentidos das palavras, ou seja, seus aspectos significativos. Vygotsky distingue dois componentes do significado das palavras: o aspecto semântico e o aspecto significativo. $\mathrm{O}$ primeiro se refere ao significado propriamente dito, ao sistema de relações objetivas que se formou no processo de desenvolvimento da palavra. Consiste num núcleo relativamente estável de compreensão da palavra, compartilhado por todas as pessoas que a utilizam (OLIVEIRA, 1995). É o que Reigota (1998) chamou de representação social.

Já o aspecto significativo é o sentido. Diz respeito ao significado da palavra para cada indivíduo, composto por relações que se referem ao contexto de uso da palavra e às vivências afetivas do indivíduo. Desse modo, o sentido liga o significado objetivo da palavra ao contexto de uso da língua e aos motivos afetivos e pessoais de seus usuários (OLIVEIRA, 1995). Seria, portanto, a dimensão microgenética, que tratamos a seguir.

Por exemplo, podemos pensar juntos na palavra piscina. Com essa palavra podemos nos comunicar, pois há nela um caráter generalizante que se refere a um tanque artificial para natação. No entanto, essa mesma expressão pode evocar sentimentos e lembranças agradáveis ou desagradáveis, e isso irá depender das experiências passadas de cada um. Embora possua um mesmo significado, pode refletir diferentes sentidos.

Assim, quando nos propomos a investigar determinado conceito, temos que levar em conta como os grupos constroem o significado do mesmo, e, também, considerar que cada indivíduo dará um sentido particular a esse mesmo conceito. Se a cultura permite a apropriação de significados, essa apropriação não se dá apenas a nível semântico, mas também a nível significativo.

Em síntese, a cultura tem um papel importante no condicionamento da percepção e valores ambientais, e o meio ambiente é avaliado de acordo com as experiências das pessoas, os antecedentes socioeconômicos e as aspirações. À medida que a sociedade e a cultura modificam-se, podem mudar a atitude para com o meio ambiente.

\subsection{A dimensão microgenética}

Essa perspectiva diz respeito à maneira particular com que cada indivíduo interage com o meio ambiente. Muitas vezes negligenciada por ser de difícil acesso investigativo, essa dimensão é fundamental, pois é ela que nos impede de cair em uma postura determinista, ora biológica, ora social.

As atitudes em relação ao meio ambiente (físico, biológico ou social) podem ser reflexo das variações bioquímicas e fisiológicas individuais. As glândulas endócrinas, por exemplo, atuam no controle do temperamento e, ao liberarem hormônios no sangue, tem efeitos nas emoções e nas sensações de bem-estar das pessoas. Até mesmo o encéfalo possui variações. Por isso, diferentes indivíduos desenvolvem distintas habilidades e relações com o meio ambiente, embora possam estar presentes em um mesmo meio social (TUAN, 1980).

Além das inúmeras diferenças individuais associadas aos cinco sentidos (sensibilidade à cor, percepção auditiva, sensibilidade tátil etc.), existem aquelas ligadas à personalidade. Essa individualidade, muitas vezes, transcende as forças culturais e cada indivíduo responde ao lugar e atribui valor a ele de maneira diferente (TUAN, 1983). "Todos os homens compartilham atitudes e perspectivas comuns, contudo a visão que cada pessoa tem do mundo é única" (TUAN, 1980, p.285).

Se os elementos e fenômenos naturais são variados, mais variada ainda é a maneira como as pessoas percebem tais fatos e os avaliam. Se diferentes grupos sociais não 
enxergam a mesma realidade, tampouco duas pessoas fazem a mesma avaliação do meio ambiente (TUAN, 1980).

Muito do que percebemos tem valor para nós, não somente para a sobrevivência biológica como também para propiciar algumas satisfações que estão enraizadas na cultura. No entanto, não existem somente valores pautados em nossas necessidades biológicas ou determinados por nossa cultura, também há valores pessoais construídos no intercâmbio com essa cultura (TUAN, 1980).

Esse fato pode estar relacionado à ideia de sentido descrita na dimensão anterior, ou seja, ao aspecto significativo de um conceito para cada pessoa. Para Oliveira (1995), o sentido da palavra liga seu significado objetivo ao contexto de uso da língua e aos motivos afetivos e pessoais de seus usuários. Desse modo, a experiência individual é sempre mais complexa do que a generalização contida nos signos.

Ao percebermos os elementos do mundo real, fazemos inferências baseadas em conhecimentos adquiridos previamente e em informações sobre a situação presente, interpretando os dados perceptuais à luz de conteúdos psicológicos próprios. A relevância dos objetos da atenção voluntária está relacionada à atividade desenvolvida pelo indivíduo e ao seu significado, sendo, portanto, construída ao longo do seu desenvolvimento em interação com o meio em que vive (OLIVEIRA, 1995).

Essa atribuição de significados e valores se deve, segundo Tuan (1983) não somente à cultura (pois pessoas de diversas culturas dividem seu mundo e atribuem diferentes valores às suas partes) e às características biológicas humanas, mas incluem as experiências pessoais. Essas experiências, entendidas como "as diferentes maneiras através das quais uma pessoa conhece e constrói a realidade" (TUAN, 1983, p.9), se devem à capacidade de aprender a partir da própria vivência. E é essa vivência que nos permite construir nosso meio ambiente particular. Embora os estímulos sensoriais sejam infinitos, aquilo que decidimos prestar atenção é um acidente individual das forças culturais de determinada época (TUAN, 1980).

Os laços afetivos dos seres humanos para com o meio ambiente, denominados conjuntamente por Tuan (1980) de topofilia, são construídos nas experiências individuais. A estética (entendida como a sensação de beleza ou prazer visual), o contato corporal ou físico com determinado meio ambiente, a sensação de bem-estar mental e a afeição pela familiaridade (fruto da consciência do passado e das experiências prévias), fazem parte dessa dimensão microgenética.

Cada indivíduo constrói e reconstrói seu mundo interior através do mundo exterior, num processo contínuo, aonde os sentidos (significados particulares) vão sendo firmados. É essa ideia que nos permite dizer que cada um cria as suas próprias relações de interesse e, assim, seu próprio meio ambiente. Damos, no decorrer de nossas vidas, identidade aos elementos que nos cercam. Temos como certo a existência dos elementos ambientais (físicos, biológicos e sociais), contudo, ao pensarmos e agirmos sobre eles, os mesmos assumem significados particulares para cada um de nós; logo, adquirem sentidos distintos.

Tuan $(1980,1983)$, discute a sua concepção de lugar como algo acrescido de valor. Para ele, o lugar é um mundo de significados organizados, um centro de significados construídos pela experiência. Sua ideia é semelhante à nossa abordagem do meio ambiente, que também é compreendido como centro de significados.

Isso implica dizer que, na medida em que conhecemos melhor os elementos que nos cercam, que passamos a experienciá-los, passamos a dotá-los de maior ou menor valor. Essa experiência refere-se, como já dissemos, à capacidade que temos de aprender a partir de nossa vivência. 
"Experienciar é aprender; significa atuar sobre o dado e criar a partir dele" (TUAN, 1983, p.10), portanto, algo que se dá individualmente. Se, para o autor, o espaço transforma-se em lugar à medida que adquire definição e significado, o mesmo podemos dizer dos elementos do ambiente ao se transformarem em meio ambiente. Logo, o valor que se dá a esses elementos refere-se a uma relação particular.

Nossa visão de mundo é sustentada pelas estruturas da experiência individual e pelo conhecimento conceitual. Objetos, fenômenos ou situações referentes ao meio ambiente físico, biológico ou social, percebidos por uma pessoa, podem não ser notados por outra. Certas coisas, para um indivíduo, possuem visibilidade ou significado, outras não. São as nossas emoções e pensamentos que dão colorido à nossa experiência e nos fazem ver isso ou aquilo como relevante (TUAN, 1975, 1983).

Por exemplo, um morador recente pode ver seu bairro simplesmente como um conglomerado de casas e prédios, mas outra pessoa que nesse mesmo bairro experienciou momentos prazerosos em sua infância, que cultivou amizades, o enxerga e o valoriza de maneira distinta. De igual modo, alguém que não vê as políticas públicas como importantes para sua vida, não irá se preocupar em votar neste ou naquele candidato a prefeito ou vereador. Logo, os significados individuais da experiência individual influem na maneira como nos relacionamos com os elementos ambientais.

Essas colocações estão de acordo com o conceito de meio ambiente discutido a seguir. $\mathrm{O}$ meio ambiente diz respeito aos elementos que envolvem ou cercam um indivíduo em particular, que, para ele, são relevantes e com os quais ele entra em interação efetiva. Não é somente caracterizado por meio da distribuição geográfica e temporal, mas, principalmente, por ser um espaço definido pelas atividades do próprio ser. É determinado em função de peculiaridades morfofisiológicas e ontogenéticas, sendo uma propriedade inerente aos seres vivos, portanto, faz referência aos fenômenos que entram efetivamente em relação com um organismo particular, que são imediatos, operacionalmente diretos e significativos.

\section{$3 \mathrm{O}$ meio ambiente, o homem e as quatro dimensões}

Defendemos que o conceito de meio ambiente deva considerar as características de cada reino, assim como, os componentes e relações que constituem o espaço no qual um organismo vive, isso porque a dependência dos seres em relação às características do ambiente varia de uma espécie para outra.

Um organismo $A$, por exemplo, interage com determinados elementos do ambiente que não necessariamente são os mesmos com os quais um organismo $B$ interage. Mesmo pertencentes ao ambiente, cada um possui seu ambiente particular ou mais especificamente, seu meio ambiente. E isso é válido para seres não humanos e humanos.

Um meio ambiente é, nesse sentido, algo que envolve ou cerca um indivíduo em particular, "é a penumbra das condições externas que para ele são relevantes em face das interações efetivas que mantêm com aqueles aspectos do mundo exterior" (LEWONTIN, 2002, p.54), ou seja, varia de acordo com o que é relevante para o organismo.

Os seres selecionam quais elementos do mundo exterior devem estar presentes para a constituição dos seus meios ambientes e quais relações entre esses componentes são relevantes para os mesmos. Um meio ambiente é caracterizado como um espaço definido pelas atividades dos próprios seres (LEWONTIN, 2002). Assim, os indivíduos determinam os aspectos do mundo exterior que para eles são relevantes, em função de peculiaridades de sua morfologia e metabolismo, construindo ativamente seus arredores ou mundo externo. 
No caso dos seres humanos, em função de nossa cultura, de nosso desenvolvimento e de nossos interesses particulares.

Retomando o trabalho de Mason e Langenheim (1957), os autores ponderam que não são todos os elementos do ambiente com os quais um organismo interage momentaneamente. Utilizando os conceitos de ambiente operacional e ambiente potencial os autores fazem duas considerações importantes: a primeira é que existem fenômenos que são imediatos e operacionalmente diretos e significativos para um organismo, e que compõe seu ambiente particular; a segunda é que existem fenômenos que não são imediatamente utilizados, mas que estão em condição futura de serem empregados operacionalmente.

Para se evitar uma interpretação polissêmica da expressão ambiente (environment), Mason e Langenheim (1957) utilizam os adjetivos operacional e potencial, para se referirem, respectivamente, aos fenômenos que entram efetivamente em relação com um organismo particular e aos fenômenos que são capazes de entrar em reação com esse organismo, mas que ainda não foram chamados a fazer. Para nós, essas expressões constituem, respectivamente, o meio ambiente e o ambiente.

Portanto, o ambiente operacional, ou como sugerimos, o meio ambiente, é um conceito que está direcionado ao organismo, a um indivíduo em particular. Essa ideia, também encontrada na noção de umwelt de Uexküll (1951), nos permite afirmar que a expressão ambiente não pode ser aplicada com o mesmo sentido a todos os seres vivos, os quais apresentam características morfofisiológicas distintas.

A expressão umwelt (um, à volta e welt, mundo), utilizada no sentido de relevant environmental, diz respeito àquele ambiente percebido por determinado organismo. Corresponde ao ambiente comportamental que é próprio de uma dada espécie e que é construído por um conjunto de estímulos dotados de valores e significados (KLOPFER, 1969). Essa expressão marca a diferença entre o mundo tal como existe em si e o mundo enquanto mundo deste ou daquele ser vivo. Trata-se de um aspecto do mundo ao qual o organismo se dirige, é o meio ambiente de comportamento, que se opõe àquele geográfico (MERLEAU-PONTY, 2000).

Umwelt corresponderia ao mundo circundante, ao entorno, ao mundo associado, ou, como acreditamos, à expressão meio ambiente. Como consequência das propriedades dos órgãos dos sentidos, do metabolismo, do sistema nervoso e da própria forma do organismo, haveria uma justaposição espacial e temporal de diferentes elementos do mundo que produziriam, assim, um entorno ou mundo externo relevante para o organismo (LEWONTIN, 2002). Esse mundo exterior seria destilado pelo organismo, que, por meio dos dados sensoriais obtidos, poderia responder-lhe com determinadas ações (MERLEAUPONTY, 2000).

Nesse sentido, compreender a relação entre organismo e meio ambiente é reconhecer os signos que a espécie é capaz de perceber, é relacioná-los com suas ações, é definir seu círculo funcional. Logo, o meio ambiente corresponde à relação específica que os seres constroem e mantêm com o mundo. Um animal, por exemplo, só percebe o que deve perceber, leva em conta seus signos e ignora o resto. Isso ocorre devido a seus diferentes receptores e efetores, também denominados de órgãos perceptivos e operacionais (HEREDIA, 2011).

Para Uexküll (1951), cada animal possui determinados órgãos para receber os efeitos do mundo exterior, denominados de receptores ou órgãos dos sentidos. A estrutura desses receptores influência sobre quais efeitos do mundo exterior exercem um estímulo e quais não. A soma desses estímulos forma um mundo circundante. Portanto, cada espécie e cada organismo vivem em um mundo especialmente disposto para ele. 
A biologia de um organismo determina o seu meio efetivo e estabelece a maneira pela qual os sinais físicos externos são incorporados. Os elementos externos do mundo físico e biótico passariam por um filtro transformador criado pela biologia específica de cada indivíduo, de cada espécie, e é justamente o resultado dessa transformação que atinge o organismo e se torna relevante para ele (LEWONTIN, 2002). "Cada sujeito tece suas relações como os fios de uma teia de aranha com certas características das coisas e os entrelaça para fazer uma rede que mantém sua existência" (UEXKÜLL, 1965, apud MERLEAU-PONTY, 2000, p.285).

Essa ideia da existência de um ambiente particular (meio ambiente), distinto de um ambiente total (ambiente) é também destacada no trabalho de Tuan (1965). Na tentativa de diferenciar dois conceitos, ambiente (environment) e mundo (world), o autor cita os trabalhos de Josef Pieper, que aponta diferenças entre os "mundos" que cercam cada indivíduo. Fazendo uso da expressão world como sinônimo de campo de relações o filósofo discorre que apenas uma entidade capaz de se relacionar, isto é, somente os seres vivos possuem um mundo. Uma rocha, por exemplo, não possui um campo de relações, ou seja, não atua sobre o ambiente físico, embora ocupe um lugar e componha a natureza.

Nesse sentido, uma planta possui um mundo, sobre o qual age, mais limitado do que um animal que se locomove. Consequentemente, o mundo humano, por assim dizer, é mais representativo que o mundo dos demais animais, uma vez que o Homo sapiens possui uma gama maior de interações (TUAN, 1965). Assim, se o termo mundo, de Pieper, for substituído por meio ambiente, teremos, também, uma distinção clara entre as expressões ambiente e meio ambiente.

No contexto das sociedades humanas podemos compreender o meio ambiente não como a soma de tudo que existe, mas como um

[...] lugar determinado ou percebido, onde os elementos naturais e sociais estão em relações dinâmicas e em interação. Essas relações implicam processos de criação cultural e tecnológica e processos históricos e sociais de transformação do meio natural e construído (REIGOTA, 1998, p.14).

O meio ambiente humano é determinado temporalmente e percebido em função de representações particulares; está em relação dinâmica no sentido de que é permanentemente construído e, portanto, estabelecido e caracterizado por diferentes culturas em espaços específicos (REIGOTA, 1998, 2009). Essa entidade é compreendida como um espaço relacional no qual o indivíduo está inserido e age sobre todo um sistema social, político e econômico, pois é capaz de percebê-lo. Assim, construímos nosso próprio mundo externo, nosso umwelt, nosso meio ambiente subsidiados por processos sígnicos (perceptivos), ou seja, pelas atividades receptoras e efetoras que caracterizam a nossa espécie, mas que variam de indivíduo para indivíduo.

Elaboramos, portanto, esquemas mentais que estão intimamente relacionados com as experiências individuais de cada um. Cada ser humano está cercado por um mundo adequado ou acomodado (UEXKÜLL, 1951), que se refere ao mundo circundante ou ao meio ambiente.

Essa abordagem do conceito de meio ambiente está diretamente relacionada com as quatro dimensões da relação homem - meio ambiente (filogenética, ontogenética, sociogenética e microgenética), isso porque passa a considerar não somente aspectos biológicos e evolutivos comuns à determinada espécie, como também perceptuais e sígnicos, sendo esse último aspecto influenciado pelo contexto histórico-social no caso da espécie humana. Portanto, a síntese pretendida neste trabalho está na proposta de um conceito integrativo de meio ambiente, que leve em conta essas quatro dimensões. 


\section{Algumas reflexões}

Vimos que, para Vygotsky, as funções psicológicas superiores, típicas do ser humano, são influenciadas tanto pelas características biológicas de nossa espécie (percepção escalar, segmentação, egocentrismo e linguagem simbólica), quanto construídas ao longo de nossa história. Como a relação homem-mundo é mediada por instrumentos e símbolos desenvolvidos no interior da vida social, é enquanto ser cultural que criamos nossa forma de ação no mundo e reconstruímos pessoalmente por meio de sínteses particulares nossas experiências e significados.

Pensar a relação entre o homem e o meio ambiente implica incluir as quatro dimensões discutidas: filogenética, ontogenética, sociogenética e microgenética. E, assim, abordar de maneira particular a relação de um indivíduo com o seu meio ambiente, visto que se trata de algo construído individualmente, mas dentro de uma coletividade.

No entanto, do mesmo modo que não podemos adotar uma abordagem sociodeterminista ou biodeterminista, devemos nos policiar para que não sejamos microdeterministas, ou seja, para que não interpretemos as ações pessoais do sujeito para com seu meio ambiente (sejam elas, positivas ou negativas) como imutáveis. Isso poderia levar a certo pessimismo, onde argumentos do tipo o sujeito percebe aquilo que the convém, ele atua sobre os elementos ambientais (físicos, biológicos ou sociais) que quer, que julga importante ou cada um visualiza aquilo que é de seu interesse, que para ele tem valor, se tornariam únicos e prevalentes.

Quando Tuan $(1975,1983)$ argumenta que certas coisas para um indivíduo possuem visibilidade ou significado, já outras não, a questão não está em, meramente, nos conformar que o sujeito enxerga o meio ambiente de dada maneira e ponto, e com ele assim se relaciona. Para nós, a questão estaria em como tornar algo significativo para alguém?, ou melhor, em como aflorar o senso de meio ambiente? para que as interações e relações entre os sujeitos e entre os homens e os elementos físicos e demais elementos biológicos sejam as mais coerentes possíveis.

Se existem inúmeras possibilidades de interação com os elementos ambientais, inúmeras experiências pessoais e, consequentemente, infinitos modos de construção de valores, como fazer para que alguns indivíduos passem a dar relevância às relações que julgamos positivas? Como fazer, por exemplo, com que uma pessoa passe a valorizar essa ou aquela relação social, essa ou aquela relação ambiental? Como fazer para que uma pessoa perceba que a manutenção de sua cidade é relevante ou que certos ambientes naturais são importantes?

Tuan (1975), embora de maneira discreta, nos aponta algumas possibilidades. Aflorar o senso de meio ambiente, de modo que possamos visualizar elementos antes não tidos como relevantes, seria a função de três esferas: da Arte, da Educação e da Política. Quando olhamos algo como uma cena panorâmica, por exemplo, nos detemos a certos pontos de interesse e isso igualmente poderia ser ampliado para qualquer fenômeno, seja físico, biológico ou social. No entanto, devido à nossa capacidade simbólica, podemos criar pontos de interesse, ou seja, tornar os elementos visíveis.

Para Tuan (1975) a arte dá visibilidade aos sentimentos e o artista é capaz de criar centros de significados. A literatura, por exemplo, busca dar essa visibilidade às experiências íntimas, chama atenção para áreas da experiência que, de outro modo, passariam despercebidas. Estaria na arte o poder de ativar a sensibilidade, ligando-se assim à estética, ou seja, à sensação de beleza ou prazer visual.

No que se refere à educação, é na escola que aprendemos sobre os vários meios ambientes e sobre os lugares (TUAN, 1975). A educação promove o contato com 
situações que não são fruto da experiência direta (pois não podemos vivenciar todos os meios ambientes), bem como o intercâmbio de experiências particulares e visões de mundo por meio das relações interpessoais mediadas. Acreditamos que é por meio das Ciências Naturais e Humanas que muitos elementos ambientais podem se tornar visíveis.

Os livros, por exemplo, disponibilizam através de imagens e textos o contato com outros ambientes e com o meio ambiente físico, biológico e social de outros grupos e indivíduos. Possibilitam conhecer a própria história, permitindo a construção de identidades, afinal conhecer um lugar é, também, conhecer seu passado (TUAN, 1975).

As ações políticas também poderiam criar um senso de meio ambiente. A cidade é um lugar politicamente organizado e a função de seu governo representativo é manter a imagem da cidade, isto é, sua visibilidade. Portanto, políticas que promovam a valorização de suas qualidades são fundamentais. Podem, por exemplo, reavivar o sentido de orgulho e promover a construção de uma identidade (TUAN, 1975). A revitalização de uma praça dá a ela uma visibilidade e as pessoas, que antes não a enxergavam, passam a frequentá-la, gerando novas relações interpessoais e, assim, novos sentidos.

Acreditamos que essas três esferas citadas por Tuan (1975) e ainda pouco exploradas, quando atuam juntas, podem contribuir para a construção de meios ambientes individuais com um maior número de elementos significativos, sendo que o modo como percebemos tais elementos reflete, também, as dimensões filogenética, ontogenética, sociogenética e microgenética da relação homem - meio ambiente.

\section{Referências}

BEGON, M.; TOWNSEND, C. R.; HARPER, J. L. Ecologia: de Indivíduos a Ecossistemas. 4ed. Porto Alegre: Artmed, 2007.

BOEGER, W.A.P. O tapete de Penélope: o relacionamento entre as espécies e a evolução orgânica. São Paulo: Editora UNESP, 2009.

BRANCO, S.M.; ROCHA, A.A. Ecologia: Educação Ambiental - ciências do ambiente para universitários. São Paulo: CETESB, 1980.

BRANCO, S.M. Conflitos conceituais nos estudos sobre meio ambiente. Estudos Avançados, São Paulo, v.9, n.23, p.217-233, jan/abril, 1995.

CARVALHO, I.C. de M. Educação ambiental: a formação do sujeito ecológico. São Paulo: Cortez, 2008.

COLLINGWOOD, R.G. A ideia da natureza. Lisboa: Editorial Presença, 1978.

GONÇALVES, C.W.P. Os (des)caminhos do meio ambiente. 12ed. São Paulo: Contexto, 2005.

GOODE, J.P. The Human Response to the Physical Environment. The Elementary School Teacher, Chicago, v.4, n.5, p.271-282, jan., 1904.

HEREDIA, J.M. Etologia animal, ontologia y biopolítica en Jakob von Uexküll. Filosofia e História da Biologia, v. 6, n.1, p.69-86, jan./jun., 2011.

KLOPFER, P. H. Habitats and territories: a study of the use of space by animals. New York: London, 1969.

LENOBLE, R. História da ideia de Natureza. Lisboa: Edições 70, 2002. 
LEWONTIN, R.C. A tripla bélice: gene, organismo e ambiente. São Paulo: Companhia das Letras, 2002.

MASON, H. L.; LANGENHEIM J. H. Language Analysis and the Concept "Environment". Ecology, Washington, v.38, n.2, p.325-340, abril.1957.

MERLEAU-PONTY, M. A Natureza. São Paulo: Martins Fontes, 2000.

OLIVEIRA, M. K. Pensar a educação: contribuições de Vygotsky In Piaget - Vygotsky: novas contribuições para o debate. Ged. São Paulo: Editora Ática, 2006.

OLIVEIRA, M.K. Vygostsky: aprendizado e desenvolvimento, um processo sócio-histórico. São Paulo: Scipione, 1995.

PIAGET, J. A representação do mundo na criança. Trad. de Adail Ubirajara Sobral. Aparecida: Ideias \& Letras, 2005.

REIGOTA, M. O que é Educação Ambiental. 2ed. São Paulo: Brasiliense, 2009. Coleção primeiros passos, 292.

REIGOTA, M. Meio ambiente e representação social. 3ed. São Paulo: Cortez, 1998.

RIBEIRO, J.A.G.; CAVASSAN, O.; CARAMASCHI, S. Diferentes percepciones de un mismo ambiente: la cuestión del género en la Enseñanza de la Ciencia. Góndola, Enseñanza y Aprendizaje de las Ciencias, Colômbia, v.6, n.2, p.51-62, dez., 2011.

RIBEIRO, J.A.G.; CAVASSAN, O.; CARAMASCHI, S. Discutindo a questão do gênero no ensino de botánica e ecologia: como meninos e meninas percebem os elementos de um mesmo ambiente. In CAPELLINI, V. L. M. F.; ZANATA, E. M.; SILVA, L. F.; LEPRE, R. M. (Orgs.). Formação de professores: compromissos e desafios da educação pública. São Paulo: Cultura Acadêmica, v.2. 2013.

THOMAS, K. O homem e o mundo natural: mudanças de atitude em relação às plantas e aos animais (1500-1800). São Paulo: Companhia das Letras, 2010.

TUAN, Y.F. Espaço e Lugar: a perspectiva da experiência. Trad. de Lívia de Oliveira. São Paulo: DIFEL, 1983.

TUAN, Y.F. Topofilia: um estudo da percepção, atitudes e valores do meio ambiente. Trad. de Lívia de Oliveira. São Paulo: DIFEL, 1980.

TUAN, Y.F. Place: an experiential perspective. Geographical Review, New York, v. 65, n.2, p.151-165, abril, 1975.

TUAN, Y.F. "Environment" and "World". The Professional Geographer, Washington, v.17, n.5, p.6-8, set., 1965.

UEXKÜLL, J. von. Ideas para una concepción biológica del mundo. Buenos Aires: Espasa-Calpe, 1951.

VESTENA, C.L.B. Piaget e a questão ambiental: sujeito epistêmico, diagnóstico e considerações educacionais. São Paulo: Cultura Acadêmica, 2011.

VYGOTSKY, L.S. A construção do pensamento e da linguagem. Trad. de Paulo Bezerra. São Paulo: Martins Fontes, 2001 
VYGOTSKY, L.S.; LURIA, A. R. Estudos sobre a história do comportamento: símios, homem primitivo e criança. Trad. de Lólio Lourenço de Oliveira. In GOLOD, V.I.; KNOX, J.E. (Ed.). Porto Alegre: Artes Médicas, 1996.

VYGOTSKY, L.S. A formação social da mente: o desenvolvimento dos processos psicológicos superiores. COLE, M. et al. (Orgs.). São Paulo: Martins fontes, 1991.

WILSON, E. O. Da natureza bumana. Trad. de Geraldo Florsheim e Eduardo D’Ambrosio. São Paulo: Edusp, 1981.

Artigo submetido em 29/04/2013

Artigo aprovado em 23/09/2013 